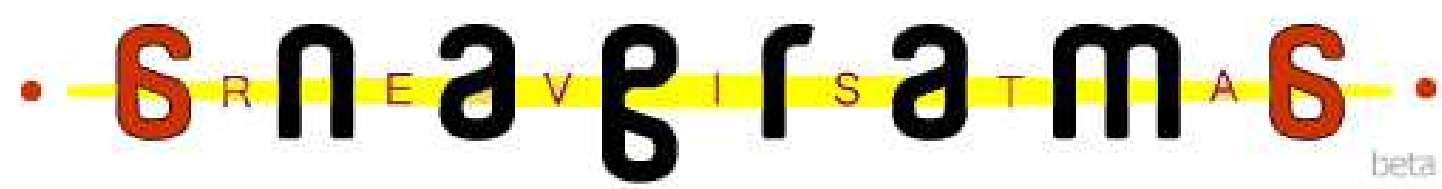

\section{Horas de Consolo: o lugar da IURD na madrugada televisiua brasileira}

Emanuelle Gonçalues Brandão Rodrigues ${ }^{1}$

José Guibson Dantas ${ }^{2}$

\section{Resumo}

A presença de instituições religiosas no espaço televisivo brasileiro tem se tornado cada vez mais eminente, o que não ocorre por acaso, já que a televisão se constitui ainda hoje como uma forte mediação entre emissor e receptor em muitos países, especialmente nos latino-americanos. A questão a qual debatemos nesse trabalho gira em torno da relação entre os dois polos do processo comunicacional no que toca a construção, desenvolvimento, emissão, recepção e feedback do discurso televisivo dos programas da Igreja Universal na madrugada da Rede Record. Para tanto, o estudo, ao mesmo tempo em que descreve a história e atuação dessa igreja na televisão, ele se propõe a analisar a relação do discurso dos programas televisivos com o contexto em que a Universal surgiu, a lógica das mensagens e a relação disso com o público-alvo.

Palauras-chaue: Comunicação; Cultura; Igreja Universal; Televisão.

\section{A Igreja Universal no Brasil: origem e características}

A expansão das igrejas neopentecostais no Brasil vem chamando a atenção da academia e dando origem a diversas pesquisas interdisciplinares sobre o assunto, sendo também tema para comentários e análises das imprensas brasileira e internacional. $\mathrm{O}$ fato se dá, entre outros motivos, pelo uso incessante da mídia para difusão da fé, grande participação política na bancada partidária e o poderio econômico dessas instituições.

\footnotetext{
${ }^{1}$ Estudante de graduação do $6^{\circ}$ período de Comunicação Social com habilitação em Relações Públicas da Universidade Federal de Alagoas, e-mail: manugbr1@ hotmail.com

${ }^{2}$ Orientador do trabalho. Doutor em Ciências da Comunicação pela Universidade de Málaga e professor do curso de Comunicação Social da Universidade Federal de Alagoas, email: joseguibson@ gmail.com
} 
O neopentecostalismo se originou no final da década de 1970, tendo suas raízes no "Pentecostalismo Clássico", que surgiu no Brasil na década de 1910 com a Congregação Cristã (1910) e Assembleia de Deus (1911), caracterizado pela ênfase no dom de línguas, anticristianismo, na crença da volta de Cristo e radical sectarismo e ascetismo de rejeição ao mundo exterior (MARIANO, 2005, p.29).

Mais adiante, a partir dos anos de 1950, surgiram igrejas mais modernas e um pouco diferenciadas das clássicas, dando ênfase à cura divina, as quais deram início à segunda onda pentecostal, o Deuteropentecostalimo. São elas a Evangelho Quadrangular (1951), a Brasil para Cristo (1955) e a Deus é Amor (1962). A terceira e última onde foi intitulada de Neopentecostalismo e se iniciou no fim dos anos de 1970, tendo como instituição propulsora a Igreja Universal do Reino de Deus (1977). Destacaram-se também nesta corrente a Igreja Internacional da Graça de Deus (1980), a Renascer em Cristo (1986) e, recentemente, a Igreja Mundial do Poder de Deus (1998).

São as igrejas neopentecostais "que realizaram as mais profundas acomodações à sociedade, abandonando vários traços sectários, hábitos ascéticos e o velho estereótipo pelo qual os crentes eram reconhecidos e, implacavelmente, estigmatizados." (Ibid., p.8). Complementando o pensamento de Mariano, Dantas frisa que

para entender o crescimento quantitativo das igrejas neopentecostais, é importante salientar que elas procuram aproximar-se do contexto popular, dialogando com o povo na mesma linguagem utilizada nos subúrbios e na periferia, recuperando um tipo de religiosidade muito viva na cultura popular, valorizando e reforçando o fascínio que o sagrado exerce sobre o povo. (DANTAS, 2006, p.61)

Nesse panorama surge a Igreja Universal do Reino de Deus (IURD), fundada em 9 de julho de 1977, por Edir Macedo em parceria com Roberto Augusto Lopes, Romildo Ribeiro Soares e os irmãos Samuel e Fidelis Coutinho, na zona norte do Rio de Janeiro. A IURD emergiu no cenário brasileiro em um contexto permeado por crises econômicas, conflitos políticos e religiosos, e, com merecido destaque, à expansão e desenvolvimento em larga escala dos meios de comunicação de massa, especialmente a televisão, que veio influenciar decisivamente a forma como o povo brasileiro passou a se enxergar e também lidar com o governo e as demais instituições sociais.

Pode-se dizer que as circunstâncias em que a Universal surgiu foram favoráveis para sua acelerada expansão, operando com um discurso que enfatizava a prosperidade e o contato direto com o Sagrado, onde os indivíduos, uma vez abençoados, teriam em suas 
vidas socioeconômicas melhoras por intermédio da "ação divina", o que se constituía como algo inviável no contexto brasileiro dos anos 80 , com as instabilidades sociais e mudança do regime político da época (RODRIGUES, 2012, 40).

Devido ao estilo centralizador de Macedo, a parceria com os outros fundadores da instituição foi rompida, ficando a Igreja Universal sob os domínios dele. Muitas características da instituição foram herdadas de seu líder, que antes de criar a Universal, peregrinou por várias instituições religiosas, o que lhe conferiu profundo conhecimento da realidade social e cultura popular brasileira, o que favorece o crescimento vertiginoso dos públicos da IURD se comparados aos das igrejas tradicionais; sendo assim, o caráter híbrido de sua liturgia e os aspectos sincréticos de sua ideologia são - somados à constante utilização dos meios de comunicação de massa para propagação da fé - alguns dos motivos de seu grande sucesso.

Segundo Oliveira, "a falta de diálogo entre as igrejas e as culturas autóctones gerou uma evangelização do tipo colonizadora e opressora" (OLIVEIRA, 2004, p.30), o que causou uma fratura cultural na população brasileira. "Conforme os Censos Demográficos do IBGE, os evangélicos perfaziam apenas $2,6 \%$ da população brasileira na década de 1940. Avançaram para 3,4\% em 1950, $4 \%$ em 1960, 5,2\% em 1970, 6,6\% em 1980, $9 \%$ em 1991e 15,4\% em 2000, ano em que somava 26.184.941 de pessoas." (MARIANO, 2012, p.121). Pode-se, em parte, atribuir esse crescimento do número de evangélicos ao surgimento do Neopentecostalismo no fim dos anos de 1970.

Em 1980, a Igreja Universal já havia estabelecido templos nas principais cidades do Brasil, como Rio de Janeiro, São Paulo e Minas Gerais. Em 1985, ela já contava com 195 templos pelo Brasil, e, em 1989 esse número subiu para 365. Na década de 1990, a IURD elevou seu número de adeptos no Brasil de 269 mil para mais de dois milhões, segundo estimativas.

Investindo maciçamente em técnicas de comunicação e seguindo o modelo empresarial das organizações comuns, a Universal também se consolida no ramo político, lançando seus candidatos na bancada partidária e abrangendo seus serviços para variados segmentos do mercado. Instituições religiosas, por lei, são isentas de taxas tributárias, de acordo com o artigo 150 da Constituição Federal. Dessa forma, há uma enorme facilidade, principalmente hoje, de criar uma igreja, o que se pode comprovar com a quantidade significativa de instituições religiosas - principalmente evangélicas - que vemos cada dia mais nas ruas das cidades. 
Seguindo o modelo administrativo episcopal - onde a igreja é comandada por bispos -, a escala hierárquica da Universal se constitui de forma vertical, estando no topo da pirâmide o bispo líder (Edir Macedo), a qual dita todas as regras da doutrina, seguido pelos bispos locais, os quais têm como responsabilidade regulamentar as linhas doutrinárias e supervisionar o trabalho dos pastores. A estes últimos cabem a missão de administrar a igreja e comandar os cultos, fazendo suas pregações evangelizadoras através das mensagens de fé. Abaixo destes, está o Instituto Bíblico Universal do Reino de Deus (IBURD), instituto que tem como responsabilidade escolher e transformar os obreiros em pastores. A estes estão subordinados vários obreiros, os quais se encarregam de auxiliar os pastores e bispos antes, durante e depois dos cultos. Eles possuem diversas funções, como receber as pessoas nos templos, visitar enfermos, auxiliar os pastores, convidar as pessoas à igreja, entre outros. Ainda pode-se contar com os missionários, que são aqueles indivíduos que têm como função bater de porta em porta levando a palavra do Senhor, segundo a doutrina iurdiana.

Ancorada no que chamamos Teologia da Prosperidade ${ }^{3}$, esta doutrina, segundo Ferrari, sustenta-se no trinômio exorcismo, cura e prosperidade.

Esse trinômio é a base teológica em cima da qual a IURD orienta e organiza a sua prática pastoral, os cultos e a estrutura de sua oferta religiosa. Nesse prisma são instituídos os ritos com sua simbologia, as normas eclesiásticas, a transmissão da visão de mundo e do sagrado, o marketing e os objetivos da Igreja. (FERRARI, 2007, p.121)

Um dos pontos centrais das estratégias de comunicação da Igreja Universal é a forma como esta se posiciona. Enquanto a maioria das igrejas pentecostais se coloca em oposição à Igreja Católica, às religiões afro-brasileiras e a outras doutrinas, a IURD age de forma estratégica, posicionando-se, de acordo com Refkalefsky (2012a), contra a Umbanda. O fato se dá porque esta agrega em seu escopo, tudo o que há de mais sincrético em termos de religiosidade e cultura popular brasileira, e, com o intuito de cooptar os públicos desse domínio, a Igreja Universal aceita a existência do mundo mágico da Umbanda (contato direto com o Sagrado, utilização de elementos simbólicos, relação de troca com as entidades, etc), mas dando um juízo de valor entre o trabalho "bom" (feito pela própria IURD) do "mal” (feito nos terreiros). (REFKALEFSKY, 2012a, p.4)

\footnotetext{
3 Teologia baseada na "crença de que o cristão deve ser próspero, saudável, feliz e vitorioso em seus empreendimentos terrenos." (MARIANO, 2004, p.124)
} 
A Igreja Universal nitidamente se utiliza do estilo populista para lidar com seus seguidores, característica herdada de seu criador, Edir Macedo. Com estilo centralizador, o bispo conduz a igreja à sua maneira, tendo apoio de todos os seus fiéis seguidores. Este poder se estende às plataformas midiáticas, onde o discurso é construído em torno de técnicas desenvolvidas de comunicação, possuindo certo grau de apelo simbólico que apenas estruturas como a televisão pode oferecer, captando sensações variadas e chamando a atenção de uma gama diversificada de telespectadores.

\section{Do templo à teleuisão: a lgreja Uniuersal e as nouas formas de euangelizar}

O presente trabalho é fruto de uma pesquisa realizada durante um projeto de Iniciação Científica. Para o artigo foram selecionados alguns recortes da investigação que consistia em verificar qual a imagem institucional da Igreja Universal para os telespectadores maceioenses. O objetivo aqui - semelhante ao do projeto - é abordar de que maneira a IURD atua no espaço televisivo e qual a influência dos públicos na construção de seu discurso, tendo como hipótese a ideia que a instituição molda sua mensagem de acordo com os públicos - que no caso da televisão não são compostos apenas por fieis -, apresentando características de organizações empresariais, demonstrando possuir interesses mercadológicos por trás da mensagem de fé.

A inserção no mundo televisivo se deu em 1980, na Rede Bandeirantes ${ }^{4}$, quando a instituição ainda estava no início de sua jornada. Na mesma época, a igreja também atuava por meio de outras plataformas midiáticas, as quais lhe deram maior visibilidade. A utilização da mídia para a difusão da fé e ideologia da IURD era parte de um plano de seu líder para expandir e voltar os holofotes para a instituição, visando cooptar mais fiéis e, consequentemente, espalhar vários templos por todos os lugares. Em 1986, Edir Macedo viajou para os Estados Unidos e lá conheceu as Igrejas Eletrônicas ${ }^{5}$ norte-americanas. A maneira como essas igrejas operavam na televisão e a grande aceitação pública dessa nova forma de evangelizar chamou a atenção do bispo, o que teve efeito na sua volta ao Brasil mais tarde.

\footnotetext{
4 De acordo com Mariano (2005, p.66), a Igreja Universal teve como primeiro programa televisivo o Despertar da Fé, na Rede Bandeirantes, em 1980, três anos após a fundação da instituição.

${ }^{5}$ Termo utilizado por alguns autores para designar o televangelismo norte-americano. "Os televangelistas, mesmo não constituindo um segmento homogêneo, voltam a comunicação para um público amplo, dentro da religiosidade cristã da maioria da população dos EUA.” (REFKALEFSKY, 2012a, p.9)
} 
Quando em 1989, Edir Macedo voltou ao Brasil, o mesmo trouxe em sua bagagem a ideia de aplicar na sociedade brasileira o televangelismo norte-americano. Para tanto, diversos aspectos estruturais dos programas televisivos aos quais ele tinha estudado durante o tempo que permaneceu nos EUA precisaram ser adaptados ao povo brasileiro. Em primeiro lugar, o bispo criticava esses programas por deixarem os fiéis muitos dispersos e à vontade quanto à sua participação. Isso ocorria porque esses programas simulavam os cultos evangélicos, não exigindo dos telespectadores nenhum tipo de manifestação. Assim, como o próprio Macedo criticou, as pessoas não eram instigadas a participar de fato da pregação, podendo a qualquer momento sair de frente da TV ou simplesmente mudar de canal. Então, no mesmo ano de sua volta, Macedo comprou a Rede Record por 45 milhões de dólares - além dos estimados 300 milhões de dólares em dívidas que este quitou -, passando a atuar, a partir dessa época, de forma mais incisiva na televisão brasileira com seus programas religiosos.

Na primeira etapa do trabalho, na qual foi revisada a literatura e história da igreja, observou-se uma série de peculiaridades, anteriormente desconhecidas. Para os leigos, as igrejas neopentecostais são iguais às demais instituições religiosas evangélicas, o que produz no senso comum certo preconceito, fruto da ausência de conhecimento sobre o assunto. Até mesmo entre as três correntes pentecostais há diferenças notáveis. Porém, o que nos interessa aqui é abordar as principais características dessa última corrente, da qual a IURD faz parte.

Com discurso maniqueísta, a Universal apresenta expressiva intolerância religiosa fato que pode ser comprovado ao assistir aos cultos e programas e ao ler sua literatura (escrita por Macedo), mostrando-se muitas vezes controverso, uma vez que a igreja se apropria de práticas e simbolismos multiculturais. Altamente organizada, a instituição segmenta seu público, adaptando-se aos diversos contextos sociais. Esses fatores são consequência de sua perspectiva de marketing bastante desenvolvida. $\mathrm{O}$ discurso resgata elementos simbólicos da cultura popular e possui mensagem de caráter emocional, despertando sentimentos e aflições mais comumente encontradas no povo brasileiro, especialmente aqueles relegados às margens da sociedade, que presenciam dia a dia a miséria e o medo nos grandes centros urbanos.

Por conta da ampla visão de mercado da instituição, seus públicos não se restringem apenas aos fiéis, mas a diversos tipos de consumidores. Um dado interessante é o fato da instituição não falar de dinheiro em seus programas. Ao contrário do muitos 
pensam, a Universal não atua igualmente em seus templos e programas televisivos. Na verdade, esses últimos servem para legitimar o seu papel na sociedade enquanto instituição religiosa preocupada com os anseios da população e, principalmente, como uma extensão dos cultos, objetivando em primeira instância convencer o telespectador a visitar seus templos.

No plano demográfico, a pesquisa do Instituto Novo Nascimento ${ }^{6}$ revelou que as igrejas renovadas e pentecostais têm públicos pertencentes às camadas populares da sociedade, onde estão os públicos com menor taxa de escolaridade. Quanto ao gênero, os evangélicos compõem-se, na sua maioria, de mulheres, possuindo um desequilíbrio acentuado, tendo $81 \%$ de mulheres para $19 \%$ de homens. O fato pode ser comprovado ao se obsevar a composição dos públicos no templo, ou até mesmo na participação majoritária do público feminino nos programas televisivos da instituição.

\section{Tabela 1}

\section{DISTRIBUIÇÃO DEMOGRÁFICA DA IURD NO BRASIL}

\begin{tabular}{|c|c|c|c|c|c|c|c|c|c|}
\hline \multicolumn{10}{|c|}{ Populaş̇o residente, por situasào do domicilio e sexo, segundo a religỉo - Brasil } \\
\hline \multirow{4}{*}{ Religiào } & \multicolumn{9}{|c|}{ Populaça residente no Brasil } \\
\hline & \multirow{3}{*}{ Total } & \multirow{3}{*}{ Homens } & \multirow{3}{*}{ Malberes } & \multicolumn{6}{|c|}{ Siruassa do domicilio e sexo } \\
\hline & & & & \multicolumn{3}{|c|}{ trbana } & \multicolumn{3}{|c|}{ Rural } \\
\hline & & & & Total & Homens & Mfulheres & Total & Homens & Mulheres \\
\hline $\begin{array}{l}\text { Igreja Universal do } \\
\text { Reino de Deus }\end{array}$ & $210185^{-}$ & 800227 & 1301660 & $1993+58$ & -55230 & $1: 38: 58$ & 108399 & $4499^{\circ}$ & $63+02$ \\
\hline
\end{tabular}

Os números apresentados na tabela 1 são de grande significância ao se analisar a programação televisiva da IURD. Assistindo aos programas, percebe-se o forte direcionamento do discurso ao público feminino, e isso ocorre por muitos motivos, mas principalmente porque a maior parte dos fiéis da IURD é composta por mulheres. A atuação delas como telespectadores e agentes produtores de conteúdo é indispensável para a IURD construir seu discurso, voltando-os para assuntos de maior interesse desse gênero, o que também permite à igreja manter sua audiência.

${ }^{6}$ (FERNANDES, 2012) 
Em pesquisa, foi realizada uma análise comparativa entre o discurso dos pastores nos templos e nos programas, através de um estudo etnográfico, onde foi observado em que grau eles se assemelhavam. Assim como no templo, na televisão são separados os programas por temática, distanciando-se apenas o Fala Que Eu Te Escuto, por ele apresentar um enfoque jornalístico. Enquanto a igreja promove cultos com abordagens diferentes a cada dia da semana (Tabela 2), os temas na televisão são separados por programas e apresentados todos os dias.

Tabela 2

\begin{tabular}{|c|c|}
\hline Culto & Dia da Semana \\
\hline Corrente da Prosperidade ou da Vida Religiosa (Empresários) & Segunda-feira \\
\hline Corrente dos Milagres ou Corrente da Saúde (Descarrego) & Terça-feira \\
\hline Corrente dos Filhos de Deus (Encontro com Deus) & Quarta-feira \\
\hline Corrente da Família (Terapia coletiva antidepressiva) & Quinta-feira \\
\hline Corrente da Libertação (Vigília dos desenganados) & Sexta-feira \\
\hline Corrente da Grandeza de Deus (Terapia do Amor) & Sábado \\
\hline Corrente do Encontro com Deus (Louvor e Adoração) & Domingo \\
\hline
\end{tabular}

Além de atentar para o discurso do pastor ou bispo responsável pelo evento, podese, nessa fase, observar a forma como os fiéis e visitantes reagem a essas mensagens, o que às vezes é surpreendente, já que nem tudo consta em livros. Comparando a uma igreja católica, por exemplo, percebe-se o alto grau de participação das pessoas nesses cultos; elas não são passivas como muitos pensam, pelo contrário, são extremamente ativas e críticas. Isso ocorre principalmente por dois fatores: primeiro essas pessoas pertencem às classes populares, logo, é uma característica própria de suas matrizes culturais essa "festividade", falando e se movendo bastante; o segundo ponto remete à atuação dos pastores diante desses públicos. Eles têm origem do próprio "povão", não sendo igual ao "clero intelectual" de algumas igrejas tradicionais, levando-os a agir igual aos seus "semelhantes".

O local não possui ícones ou um coro ao fundo, direcionando toda a atenção para o altar, onde se encontra o pastor e apenas um instrumento musical, o órgão. A linguagem é carregada de elementos simbólicos, assim como algumas práticas. No templo encontramos um grande castiçal com espaço para sete velas e um imenso portão (utilizado no culto das segundas-feiras). A Sessão do Descarrego é o culto onde mais se pode observar o caráter sincrético da IURD. Todos os pastores utilizam vestimentas brancas e os obreiros, em especial, utilizam batas, assemelhando-se a enfermeiros. Usar roupas brancas é uma 
característica de determinadas seitas africanas, o que somado aos termos utilizados no evento, como "Sessão", "Descarrego" e "Amarrado", por exemplo, faz-nos perceber a riqueza de símbolos utilizados pela igreja, demonstrando a apropriação simbólica que esta faz de outras religiões em sua liturgia. A aparência também é bastante semelhante a de enfermeiros, o que não é por acaso, já que a função desses profissionais é cuidar dos doentes. Os nomes dos demônios que eles “exorcizam" são, na verdade, os mesmos das entidades de algumas seitas.

A importância de se estudar o discurso no templo e frequentar vários cultos, assim como interagir com os fiéis, se tornou relevante no momento de analisar os programas televisivos, visto que eles servem muitas vezes como extensões dos cultos - estratégia da Universal para manter uma relação mais próxima com os fiéis, além de angariar públicos que não frequentam a igreja. Por meio de nosso estudo, comprovamos que a maioria dos programas possui narrativa explicitamente ligada a de determinados cultos da instituição, servindo também como propaganda destes.

\section{Horas de consolo: a IURD na madrugada teleuisiua}

A análise da programação televisiva foi realizada no horário da madrugada durante um período de duas semanas (20/12/2011 a 31/12/2012). A grade religiosa não é composta apenas de programas, tem-se também propaganda dos cultos (no sentido mercadológico), juntamente com os pronunciamentos do bispo Macedo, intitulados "Palavra Amiga", onde são apresentadas gravações dele no estúdio de rádio falando dos males da sociedade e tentando direcionar os espectadores ao caminho do bem, dando conselhos e até mesmo exemplos de acontecimentos passados. Esse VT é repetido várias vezes durante esse horário, o que nos leva a ideia de que a repetição, assim como a fragmentação, é uma das grandes características dessa programação, o que não acontece por acaso. Programas como o Fala Que Eu Te Escuto (enfoque jornalístico), Plantão da Fé (sobre a vida sentimental), Ponto de Luz (extensão da Sessão do Descarrego), Saindo da Crise (para os empresários), foram alguns dos produtos analisados nessa etapa.

O Fala Que Eu Te Escuto é um destaque no que se refere às estratégias de comunicação utilizadas pela Igreja Universal. O programa é marcado pelo fluxo contínuo de informações, assim como pela convergência das mídias - ao mesmo tempo que ele é transmitido, mensagens dos telespectadores no twitter aparecem no rodapé, e-mails são 
lidos, conversas via telefone e videoconferência também ocorrem em tempo real. Para cada dia é escolhido um tema diferente, que quase sempre é derivado de um assunto de grande repercussão na sociedade, especialmente porque ele é transmitido em rede nacional. Nele, o profano é apresentado em forma de imagens e temáticas violentas ou de cunho sexual como estratégia de legitimar o sagrado por meio de seu discurso maniqueísta, onde a igreja aparece como representante do "bem". O programa é bastante conhecido também pelo copo com água sacralizado que os pastores utilizam para abençoar os fieis via televisão.

O Plantão da Fé faz clara alusão à Terapia do Amor, que, ao contrário do programa que passa todos os dias, o culto só acontece aos sábados. Programa local, o pastor que apresenta é o mesmo do culto do sábado ao qual o programa faz propaganda. São abordados temas relacionados à vida sentimental, onde são mostrados clipes românticos, dados conselhos para a vida amorosa, apresentados casos - com direito a simulações -. O Diabo possui um papel especial no programa, ao qual lhe é atribuído à causa da desgraça dos casais. No final do programa, após algumas ligações e e-mails recebidos, o pastor coloca o nome das pessoas em papéis e os coloca na taça de óleo "ungido".

Com discurso ligado aos cultos de terça-feira e sexta-feira, especialmente à Sessão do Descarrego, o Ponto de Luz trata das questões de caráter espiritual, tendo forte apelo simbólico em sua narrativa. O Diabo e a "Macumba" possuem papel central no programa, conferindo a estes todos os males da sociedade. São apresentadas as características e sinais, segundo a doutrina, de pessoas possuídas ou perseguidas por entidades demoníacas - podese ver isto também no livro de Macedo, Orixás, Caboclos \& Guias: deuses ou demônios?. Além dos testemunhos e conselhos dados pelo pastor, também do culto ao qual o programa está ligado, pessoas são entrevistadas e chamadas a testemunhar. O pastor-apresentador normalmente está vestido de branco e sempre recebe ligações e e-mails com pedidos de oração.

Saindo da Crise é outro programa importante na grade televisiva da madrugada, o qual faz referência ao culto da segunda-feira, a Corrente dos Empresários, onde o enfoque é dado à vida financeira das pessoas. Assim como os outros, o apresentador é, normalmente, o pastor do próprio culto e o discurso bastante semelhante.

Aos testemunhos é reservada boa parte da programação, estando eles tanto nos programas como nos intervalos - muitos, inclusive, são repetidos durante a madrugada toda. Essencialmente iguais, eles mudam apenas os objetos e poucos detalhes das histórias, iniciando-se com a testemunha falando de si no tempo passado - com semblante triste - até 
a parte em que conhecem a igreja e se tornam fiéis, expressando a felicidade em que se encontram hoje.

Segundo as testemunhas, antes eram perdidas, cheias de dívidas, com vida precária, sem família e, quase sempre, pertencentes ao mundo das drogas, do alcoolismo ou das “seitas demoníacas". Então, através de um mediador, normalmente um amigo ou um programa da igreja - que por acaso assistiram - elas conhecem o caminho da luz e suas vidas começam a mudar. Então falam dos dízimos que nunca deixaram de pagar, dos cultos que nunca pararam de frequentar e da fé que nunca deixaram de apostar na igreja.

Logo adiante, após esta primeira parte, o quadro se abre e mostra a testemunha no presente, onde já possui casa, automóvel, família e vive uma vida feliz. Também falam das pequenas empresas que abriram - fonte de seu lucro. Vale ressaltar que esta mudança de vida se dá de forma incrível, como um caso em que a testemunha tinha uma enorme dívida no banco e após pagar o dízimo, incrivelmente e sem explicação aparente a dívida sumiu no outro dia quando ela foi olhar sua conta bancária. Os pastores atribuem isso a benevolência de Deus para com estes fiéis, abençoando a todos que acreditam piamente no seu poder e são fieis dizimistas.

O fragmento e a repetição reproduzem o cotidiano, tornando-se uma espécie de simulacro da realidade, onde a "simulação do contato atende à própria condição da recepção televisiva, que se dá no ambiente da dispersão característica à cotidianidade familiar." (GOMES, 2011, p. 115). Neste sentido, a programação televisiva da IURD parece se apropriar de algumas características do gênero telenovela, utilizando artifícios melodramáticos como estratégia de comunicação aproximativa.

No Brasil, assim como em toda a América latina, a falta de uma cultura letrada consequência da formação do próprio povo, mesmo antes da colonização europeia - fez da oralidade uma característica dominante da nação brasileira. Nesse contexto, a cultura visual também se firmou nesse cenário, o que séculos mais tarde influenciou decisivamente na predominância da televisão como meio de comunicação dominante nessa sociedade. Tendo conhecimento disso, a Igreja Universal utilizou estrategicamente os meios de comunicação de massa, especialmente a televisão, para propagar e difundir sua fé, o que fez com sucesso, atingindo níveis altos de visibilidade.

O espaço televisivo destinado a conteúdos de caráter religioso vem sofrendo mutações, assim como a própria mensagem que transita nesse meio. Esse fato é perceptível na forma como os programas da Igreja Universal são estruturadas, sofrendo transmutação 
de gênero e se adequando ao novo perfil socioeconômico e cultural da população. Nessa perspectiva, os contextos sociais em que seus telespectadores estão inseridos são aspectos fundamentais para compreender a recepção midiática e consequentemente o modo como o receptor interfere na construção do discurso televisivo. Mais que um meio de difusão de informação, a televisão se configura hoje também como mediadora, onde a "A IURD [mais do que qualquer outra igreja], ao recuperar elementos da religiosidade popular, conseguiu a partir dos traços próprios da cultura brasileira, tornar a mensagem evangélica significativa às necessidades de seus fiéis”. (OLIVEIRA, 2004, p.13)

Por não exigir a conversão dos indivíduos - sejam eles visitantes dos templos ou telespectadores -, os públicos da IURD são essencialmente transitórios. Diferente dos templos, os programas televisivos não apresentam discurso proselitista, apelando sempre para os recursos audiovisuais como clipes, videoconferências, matérias jornalísticas e outros.

Tanto nos programas como no templo, o testemunho é um dos pontos centrais e estratégicos utilizados pela instituição para reiterar seu papel evangelizador e milagroso na sociedade. Este se constitui como um elemento legitimador das práticas iurdianas enquanto reais e milagrosas, tornando-se uma das principais estratégias para comprovar seu grande poder. Em muitos casos, "a força de pressão psicológica leva à 'compreensão de significado' por uma clientela 'desejosa de sentido'.” (FERRARI, 2007, p.112), o que alguns chamam de autossugestão. Tudo o que se diz tem uma explicação coerente dos pastores e legitimadas por suas interpretações bíblicas.

Não se deve restringir a análise apenas às estruturas e à construção do discurso em formato de jornal (no caso de determinados programas) ou de espetáculo, pois as estratégias mercadológicas e de comunicação da igreja vão bem além disso. Vê-se, nesse sentido, a necessidade de um enfoque culturalista para melhor compreender o processo pelo qual a mensagem chega ao receptor de forma satisfatória para a igreja, ou seja, de uma maneira que ele entenda o discurso e se identifique com a instituição.

\section{Considerações finais}

A utilização da televisão para difusão da fé é o grande triunfo das igrejas da atualidade, principalmente na sociedade latino-americana, onde esta se constitui como 
mediação possuidora de função política, já que as instituições-casca ${ }^{7}$ enfraqueceram e a falta de representatividade do povo na política se tornou notória, transformando-se [a televisão] em uma espécie de simulacro da democracia (DANTAS, 2008, p.52). É dessa forma que as novas igrejas misturam os espaços virtuais com os reais para se solidificar e conseguir novos adeptos.

A utilização incessante dos meios de comunicação de massa é uma típica característica das igrejas neopentecostais, onde a televisão, em especial, constitui-se como mediadora entre a instituição e seus públicos, tendo como objetivo primordial levar as pessoas aos templos. Entretanto, não se pode esquecer que o conteúdo midiático é construído a partir dos interesses sociais e das pessoas que os constroem, onde elas ao mesmo tempo em que sofrem influência dos meios também são capazes de moldá-los, pois as representações dos indivíduos presentes na mídia são frutos da própria imagem que os produtores do conteúdo midiático têm da sociedade.

Nesse sentido, a Igreja Universal do Reino de Deus ganhou notória visibilidade e sucesso na sua estratégia empreendedora de tornar a instituição uma grande organização de diversos fins; e, mesmo com o aumento da concorrência religiosa pela audiência, essa instituição é, ainda hoje, um grande fenômeno a ser estudado e analisado no que se refere às práticas religiosas na contemporaneidade e sua operacionalidade nos meios de comunicação de massa.

\section{Referências Bibliográficas}

BRITTOS, Valério Cruz. Comunicação e cultura: o processo de recepção. Disponível em: <http://www.bocc.ubi.pt/pag/brittos-valerio-Comunicacao-cultura.pdf >. Acesso em $\mathrm{abr} / 2012$.

DANTAS, José Guibson. La recepción del Dios televisivo em Brasil: El poder de las mediaciones culturales. Recife: Ed. do autor, 2008.

\footnotetext{
${ }^{7}$ Termo criado por GIDDENS (2007), refere-se às instituições anteriormente designadas a desempenhar a função de formar os cidadãos, e que hoje não se fazem mais tão necessárias na vida destes. São elas, por exemplo, a igreja, o estado, a família e as escolas.
} 
Neopentecostais e as mediações culturais: o comportamento dos telespectadores diante dos programas televisivos das igrejas neopentecostais. Recife: Ed. do autor, 2006.

FERNANDES, Rubem Cesar. O Novo Nascimento. Disponível em: $<$ http://books.google.com.br/books?id=st6ZmRSfuU8C\&printsec=frontcover\#v=onepage $\& \mathrm{q} \& \mathrm{f}=$ false $>$ Acesso em abr/2012.

FERRARI, Odêmio Antônio. Bispo S/A: a Igreja Universal do Reino de Deus e o exercício de poder. $3^{\text {a }}$ edição. São Paulo: Ave-Maria, 2007.

GIDDENS, Anthony. Mundo em descontrole: o que a globalização está fazendo de nós. $6^{\text {a }}$ edição. Rio de Janeiro: Record, 2007.

GOMES, Itânia Maria M. Gênero televisivo como categoria cultural: um lugar no centro do mapa das mediações de Jesús Martín-Barbero. Disponível em: < http://revistaseletronicas.pucrs.br/ojs/index.php/revistafamecos/article/viewFile/8801/6165 >. Acesso em jan/2012.

IBGE. Censo Demográfico - 2000 - Resultados da Amostra. Disponível em: <http://www.ibge.gov.br/home/estatistica/populacao/censo2000/primeiros_resultados_amo stra/brasil/pdf/tabela_1_1_2.pdf> Acesso em fev/2012.

MACEDO, Edir. O Perfil da Mulher de Deus. Rio de Janeiro: Universal, 1997.

MACEDO, Edir. Orixás, Caboclos \& Guias: deuses ou demônios? $15^{\mathrm{a}}$ edição. Rio de Janeiro: Universal, 2005.

MARIANO, Ricardo. Expansão pentecostal no Brasil: o caso da Igreja Universal. Disponível em: <http://pt.scribd.com/doc/23220432/Ricardo-Mariano-Expansaopentecostal-no-Brasil-O-caso-da-Igreja-Universal> Acesso em abr/2012.

Neopentecostais - sociologia do novo pentecostalismo no Brasil. $2^{\mathrm{a}}$ edição. São Paulo: Loyola, 2005.

MARTÍN-BARBERO, Jesús; REY, Germán. Exercícios do ver. 2a edição. São Paulo: Senac São Paulo, 2004.

OLIVEIRA, Ivo Xavier. Igreja Universal do Reino de Deus: uma instituição inculturada? São Paulo: EP, 2004.

REFKALEFSKY, Eduardo. Comunicação e Posicionamento da Igreja Universal do Reino de Deus: um estudo de caso do Marketing Religioso. Disponível em: < http://galaxy.intercom.org.br:8180/dspace/bitstream/1904/19721/1/Eduardo\%20Refkalefsk y.pdf > Acesso em abr/2012. 
Estratégias de Comunicação da Igreja Universal do Reino de Deus, no

Brasil, e dos Televangelistas nos EUA: um estudo comparado. Disponível em: <http://galaxy.intercom.org.br:8180/dspace/bitstream/1904/16752/1/R1249-1.pdf> Acesso em mar/2012.

RODRIGUES, Jadir Gonçalves. Política, carisma, poder e mídia: lógicas interpretativas da Igreja Universal do Reino de Deus. Disponível em: < http://periodicos.pucminas.br/index.php/horizonte/article/view/422/832 > Acesso em $\mathrm{abr} / 2012$. 